\title{
Programmed body weight loss in morbidly obese women and its influence on general physical fitness, knee status and every day life activity
}

\begin{abstract}
Introduction. Obesity is a serious health and social problem. Various sources indicate that it affects approx. $20 \%$ of the world's population. It is also counted among the diseases of affluence. Excessive body weight adversely affects a number of systems in the human body, including the locomotor system. Studies have shown that there is a close relationship between obesity and either a dysfunction or osteoarthritis of knee joints.

Aim. To evaluate the impact of weight reduction on the basic parameters of the overall capacity of obese women and their well-being.

Material and methods. 7 extremely obese women aged 28-51 looking to reduce their body weight participated in the study. The weight reduction program lasted for 12 months and consisted of reported intervention. The validated survey by Johanson was used to assess the performance of the lower limbs. Each tested person filled in 3 surveys of the same kind - the first at the beginning of the research project, the second after losing $20 \mathrm{~kg}$ of body weight, and the third after 12 months of weight reduction.

Results. There has been a statistically significant decrease in body weight $(p=0.002)$ and BMI $(p=0.002)$ of women surveyed between the specific periods of observation. The pain from the knee joints decreased or was resolved through weight reduction $(p=0.004)$ in the respondents. The participants also started to take less painkillers for knee discomfort ( $p=0.005)$. Authors also noted an increase of the walking distance without rest $(\mathrm{p}=0.01)$ and less problems while walking upstairs $(\mathrm{p}=0.004)$. There was a statistically significant improvement in their self-care for the feet $(\mathrm{p}=0.003)$, as well as in the ability to use public transport $(p=0.05)$ or to do shopping $(\mathrm{p}=0.05)$. There were no significant differences in the performance of household chores, getting out of bed, using the bath or shower or in need of orthopaedic equipment.

Conclusions. Significant weight reduction in obese women proportionally reduces or relieves knee pain and improves their performance. It reduces the need for using analgesics. Weight reduction in obese people has a significant impact on improving the performance of lower limbs.
\end{abstract}

Keywords: obesity, weight reduction, quality of life.

DOI: $10.1515 /$ pjph-2016-0018

\section{INTRODUCTION}

Obesity affects some $20 \%$ of the world's population. It is regarded as a disease of affluence. Epidemiological nature of obesity is a major health and social problem [1]. Painful overuse syndromes associated with obesity affect knee joints [2-4] and lumbar spine [5]. Other research studies, both those conducted by numerous authors [6-11] and our own [12] have proven a definite causal link between obesity and knee osteoarthritis. Pain and locomotor activity limitations of obese people together with metabolic syndrome compose the whole clinical picture [13-15]. Additionally, was shown that obese people obesity have a chance to improve their functioning and restore the biological value of the tissues altered by overuse [16-20].

\section{A IM}

The aim of this study was to evaluate the impact of weight reduction on the basic parameters of the overall capability and well-being in a retrospective manner.

\section{MATERIAL AND METHODS}

Seven extremely obese women were analyzed in the study. They all underwent voluntary process of weight reduction (body weight ranged from $103 \mathrm{~kg}$ to $155 \mathrm{~kg}$, mean body weight $133 \mathrm{~kg}$ ) and aged 28-51 years (mean age 42 years).

The participants were mainly city residents, were professionally active, had secondary or higher education, and were married. All women were attending a weight reduction

\footnotetext{
${ }^{1}$ Department of Anaesthesiological and Intensive Care Nursing, Medical University of Lublin, Poland

${ }^{2}$ Chair and Department of Rehabilitation and Orthopaedics, Medical University of Lublin, Poland

${ }^{3}$ Department of Mathematics and Medical Biostatistics, Medical University of Lublin, Poland

${ }^{4}$ Gaca System in Lublin, 20-301 Lublin, Poland
} 
program in 2012 organized by Konrad Gaca Center for Weight Reduction in Lublin (P1. Centrum Odchudzania Konrada Gacy w Lublinie).

The performance of the lower limbs was examined using survey questions by Johanson [21]. This questionnaire was validated by the authors of the study. It was originally used to evaluate the performance of lower limbs with the dysfunctions of the hip joints, evaluates four equivalent domains 1) global or overall impact of the disease, 2) pain, 3) gait efficiency and 4) the ability to fulfil do everyday chores. The pain was assessed using 4 separate questions looking at its intensity, frequency of analgesics intake, the frequency of severe pain spells and frequency of pain at rest. Intensity is graded as very high, high, moderate, mild or none. The frequency of the high intensity of the pain associated with the disease was graded as follows - daily, several days per week, one day per week, one day per month or not at all. Both the frequency of severe pain at rest and the use of analgesics were assessed by 3 separate questions. Gait efficiency was evaluated through 2 questions, one of which refers to the range of walking and the second one evaluates what kind of help is needed and how often it is needed. The question about the range of walking included the following possible answers - unable to walk less than 80 meters ("a block of flats"), more than $80 \mathrm{~m}$ and less than $800 \mathrm{~m}$, more than $800 \mathrm{~m}$ and less than $1600 \mathrm{~m}$ or without restrictions. Another question regarded the five types of mobility aid - not able to walk, help from another person, underarm crutches or walkers, walking stick or one crutch, without help - combined with 5 categories of frequency.

Other questions included in the survey concerned walking upstairs, putting on socks or shoes, using public transport, bathing in bathtub, doing shopping, doing housework, and getting in and out of bed as well as sitting on and getting up from a chair.

The studied group, the so-called "Weight Reduction Leaders", filled out 3 identical surveys, the first one (initial) regarding the state of health at the beginning of a weight reduction program, the second (intermediate), after losing $20 \mathrm{~kg}$ of body weight approximately after 2-3 months of working with a personal trainer, and the third survey (final one) with body weight after about a year of participation in the project and the reduction of 45-97 kg of body weight (71 kg on average). Detailed data were obtained from the records provided by Konrad Gaca Center for Weight Reduction in Lublin. Neither the nutritional nor training programs improving metabolic processes were analyzed. Most attention was paid to the weight reduction factor and its influence over the quality of life related to health. It should be pointed out that the people surveyed were the most persistent and determined to achieve the intended purpose (weight reduction). The efficiency and accuracy of surveying was supervised by an employee of the Center for Weight Reduction, Michael Zajko, master of physiotherapy.

Verification of statistical hypotheses based on Friedman's nonparametric tests ANOVA and Kendall's coefficient of concordance, as well as and $\mathrm{Chi}^{2}$ ANOVA were used in the statistical analysis by means of Statistica 10 with significance $\mathrm{p}<0.05$.

\section{RESULTS}

A statistically significant decrease in body weight among study group participants (stage $\mathrm{I}=133 \mathrm{~kg}$, stage $\mathrm{II}=99 \mathrm{~kg}$, stage $\mathrm{III}=68 \mathrm{~kg}, \mathrm{p}=0.002$ ) and similar BMI decrease between periods of study $\left(\mathrm{Chi}^{2} \mathrm{ANOVA}=12\right.$ 29, $\left.\mathrm{p}=0.002\right)$ were noted in the process of weight reduction.

Accordingly, the body mass index in the group of "Weight Reduction Leaders" was on average: at stage I - initial stage of weight reduction: 49.99 ( $\mathrm{Me}=49.13, \mathrm{SD}=9.23)$, stage II intermediate: $37(\mathrm{Me}=35.01, \mathrm{SD}=6.74)$, at stage III - the final stage of weight reduction: $25.56(\mathrm{Me}=24.8, \mathrm{SD}=2.61)$ $(\mathrm{p}=0.002)$.

The assessment of knee pain intensity throughout different stages of weight reduction shows that the initial pain score ( $\bar{X}=3.71$ points, $\mathrm{SD}=1.38$ ) classifies the pain as very severe, while the assessment of the pain on the second stage $(\bar{X}=1.86$ points, $\mathrm{SD}=1.07)$ assessed this pain as mild, and the final score ( $\bar{X}=1.29$ points, $\mathrm{SD}=0.49$ ) showed that the majority of respondents reported no problems.

This means, a significant decrease in knee joint pain intensity was noted in the surveyed period during different stages of the weight reduction process $\left(\mathrm{Chi}^{2}=11.143, \mathrm{p}=0.004\right)$.

A similar decrease in the frequency of perceived knee pain during the previous month both: post-exercise $\left(\mathrm{Chi}^{2}=11.272\right.$, $\mathrm{p}=0.004)$ and at rest $\left(\mathrm{Chi}^{2}=8.72, \mathrm{p}=0.01\right)$ was noted at various stages of weight reduction, on the scale of 1- daily to 5- never.

Along with the above findings, respondents, at different stages of weight reduction reported a significant decrease in the frequency of analgesics intake to alleviate the ailments of the knees $\left(\mathrm{Chi}^{2}=10.571, \mathrm{p}=0.005\right)$. Baseline (initial) assessment of the frequency of painkillers use by respondents ( $\bar{X}=3.42$ points, $\mathrm{SD}=1.51$ ) classified this parameter as "quite or very often", while the control assessment $(\bar{X}=1.86$ points, $\mathrm{SD}=1.07)$ identified the frequency as "sometimes used", and the final score $(\bar{X}=1.14$ points, $\mathrm{SD}=0.38)$ showed that the majority of women surveyed did not use the analgesic treatment.

Length of walking distance without feeling the necessity to have a rest due to pain increased during the weight reduction period at different stages of weight loss (on the scale of 5- unlimited to 1 - I am unable to walk, $\left(\mathrm{Chi}^{2}=9.579, \mathrm{p}=0.01\right)$, which was accompanied by a significant decrease of difficulty in going up or down one flight of stairs in the periods studied during the process of weight reduction on the scale of 1- I cannot do this without difficulty to 5 - I can do this without difficulty $\left(\mathrm{Chi}^{2}=11.2, \mathrm{p}=0.004\right)$. Stage I (initial) $\bar{X}=3.28(\mathrm{SD}=1.38$, $\mathrm{Me}=4)$, stage II (intermediate) $\bar{X}=4.71(\mathrm{SD}=0.49, \mathrm{Me}=5)$, stage III (final) $\bar{X}=5(\mathrm{SD}=0, \mathrm{Me}=5)$.

Similarly, there was a statistically significant improvement in the individuals; ability to care about their feet during various stages of the weight reduction process (on the scale of 1I cannot do this without difficulty, to 5- I can do this without difficulty, $\mathrm{p}=0.003$ ). Also, an it has become much easier to use public transport in different periods studied in the process of weight reduction $\left(\mathrm{Chi}^{2}=6, \mathrm{p}=0.05\right)$; stage I (initial) $\bar{X}=2.29$ $(\mathrm{SD}=0.95, \mathrm{Me}=3)$, stage II (intermediate) $\bar{X}=3.00(\mathrm{SD}=0.00$, $\mathrm{Me}=3$ ), stage III (final) $\bar{X}=3.00(\mathrm{SD}=0.00, \mathrm{Me}=3)$; as well as significant differences of the surveyed women's capabilities of doing shopping in the different periods of the process of weight reduction $\left(\mathrm{Chi}^{2}=6.00, \mathrm{p}=0.05\right)$.

There were no significant differences concerning the capability to perform everyday chores at home during different periods of the process of weight reduction nor were there significant differences in the capabilities of getting out of bed or the ability to take a bath or a shower. Apart from the serious decline in demand for orthopedic equipment these changes were not statistically significant. 


\section{CONCLUSIONS}

1. Weight reduction in obese people reduces or relieves knee pain and improves physical performance.

2. Losing weight by obese people has little impact over daily life activities and doing housework chores.

Observations of the impact of weight reduction on extremely obese women points out to the beneficial effects on the performance of lower limbs and knee pain relief. The first stage of weight reduction, i.e. the reduction of about $20 \mathrm{~kg}$ let to the most beneficial changes among the surveyed group of the extremely obese women. Even further body weight drops (further $30 \mathrm{~kg}$ ) did not lead to such substantial improvements in functioning. Knee joint pains, occurring frequently to the surveyed women - "Weight Reduction Leaders" - decreased or completely ceased along with weight reduction. Our observations are consistent with those of the other authors [1,17,21], although the description of the research similar to that presented in the paper have not been encountered in the literature.

\section{REFERENCES}

1. Szymocha M, Bryła M, Maniecka-Bryła M. Epidemia otyłości XXI wieku. Zdr Publ. 2009;119(2):207-12.

2. Coggon D, Reading I, Croft P, et al. Knee osteoarthritis and obesity. Int J Obes Relat Metab Disord. 2001;25,622-7.

3. Kotowski SE, Davis KG. Influence of weight loss on musculoskeletal pain: Potential short-term relevance. Work. 2010;36(3):295-304. doi: 10.3233/ WORK 2010-1031.

4. Kwiatkowski K. Gonartroza - patomechanizm, występowanie i czynniki ryzyka. Chirurgia Kolana, Artroskopia, TraumatolSport. 2004;1:75-90.

5. Shiri R, Karppinen J, Leino-Arjas P, et al.. The association between obesity and low back pain: a meta-analysis. Am J Epidemiol. 2010;171(2):135-54.

6. Blagojevic M, Jinks C, Jeffery A, Jordan P. Risk factors for onset of osteoarthritis of the knee in older adults: a systematic review and meta-analysis. Osteoarthritis and Cartilage. 2010;18:24-33.

7. Chaganti RK, Lane NE. Risk factors for incident osteoarthritis of the hip and knee. Curr Rev Musculoskelet Med. 2011;4:99-104.
8. Cooper C, Snow S, McAlindon TE, et al. Risk factors for the incidence and progression of radiographic knee osteoarthritis. Arthritis Rheum. 2000;43:995-1000.

9. El Ayoubi N, Chaaya M, Mahfoud Z, et al. Risk factors for incident symptomatic knee osteoarthritis: A population-based case control study in Lebanon. Int J Rheum Dis. 2013;16:211-8.

10. Mork PJ, Holtermann A, Nilsen TI. Effect of body mass index and physical exercise on risk of knee and hip osteoarthritis: longitudinal data from the Norwegian HUNT Study. J Epidemiol Community Health. 2012;66:67883.

11. Wang Y, Simpson JA, Wluka AE, et al. Relationship between body adipositiy measures and risk of primary knee and hip replacement for osteoarthritis: a prospective cohort study. Arthitis Res Ther. 2009;11:R31.

12. Morawik I. Czynniki wpływające na jakość życia kobiet pomenopauzalnych przed protezoplastyką stawu biodrowego lub kolanowego podobieństwa i różnice. Praca doktorska, Lublin; 2013.

13. Issa RI, Griffin TM. Pathobiology of obesity and osteoarthritis: integrating biomechanics and inflammation. Pathobiol Aging Age Relat Dis. 2012;9:2

14. Puenpatom RA, Victor TW. Increased prevalence of metabolic syndrome in individuals with osteoarthritis: an analysis of NHANES III data. Postgrad Med. 2009;121:9-20.

15. Zhuo Q, Yang W, Chen J, Wang Y. Metabolic syndrome meets osteoarthritis. Nat Rev Rheumatol. 2012;8(12):729-37. doi: 10.1038/nrrheum.2012.135. Epub 2012 Aug 21.

16. Anandacoomarasamy A, Leibman S, Smith G, et al. Weight loss in obese people has structure-modifying effects on medial but not on lateral knee articular cartilage. Ann Rheum Dis. 2012;71:26-32

17. Felson DT, Zhang Y, Anthony JM, et al. Weight loss reduces the risk for symptomatic knee osteoarthritis in women. The Framingham Study. Ann Intern Med. 1992;116:535-9.

18. Gudbergsen H, Boesen M, Lohmander LS, et al. Weight loss is effective for symptomatic relief in obese subjects with knee osteoarthritis independently of joint damage severity assessed by high-field MRI and radiography. Osteoarthritis Cartilage. 2012;20:495-502.

19. Richette P, Poitou C, Garnero P, et al. Benefits of massive weight loss on symptoms, systemic inflammation and cartilage turnover in obese patients with knee osteoarthritis. Ann Rheum Dis. 2011;70:139-44.

20. Vincent HK, Heywood K, Connelly J, Hurley RW. Obesity and weight loss in the treatment and prevention of osteoarthritis. PM R. 2012;4(5 Suppl):S59-67.

21. Johanson NA, Charlson ME, Szatkowski TP, Ranawat CS. A Self-Administered Hip-Rating Questionnaire for the Assesment of Outcome after Total Hip Replacement. J Bone Joint Surg. 1992;74-A 587-96.

\section{Corresponding author}

Aneta Zarębska

Chair and Department of Rehabilitation and Orthopaedics,

Medical University of Lublin

8 Jaczewskiego Str., 20-954 Lublin

tel: +48817244184

E-mail: aneta.zarebska@umlub.pl 